\title{
Using Swarm Algorithm to Build Efficient Portfolio
}

\author{
Dr. Moudhir Khalid Abdul hameed \\ Department of Business Administration \\ Faculty of Administration and Economics \\ University of Tikrit \\ moudher@yahoo.com
}

\section{Dr.Nazar Khalaf Hussein}

Department of Mathematics

Faculty of computer sciences and Mathematic

University of Tikrit

Nazar.dikhil@tu.edu.iq

\author{
Dalal Salih Al Shammari \\ Department of Business Administration \\ Faculty of Administration and Economics \\ University of Tikrit \\ Dalal24salih@gmail.com
}

\section{Dr.Abdul Aziz Shwaish Abdul Hameed}

Department of Business Administration

Faculty of Administration and Economics

University of Tikrit

Abd Azeez665@tu.edu.iq

\section{Abstract.}

The increase of financial investment induce the investors, financial analysts and specialists to look for Low-risk and High-return investment opportunities, represented as investment portfolios selected and built on scientific bases such portfolios represent the best way to minimize risks and maximize returns. They called as efficient and optimal portfolios. Many developments happened on the Markowitz theory; the researchers see that the portfolio investment needs to continuous developments. This paper discussed using the optimization algorithm to build the optimal portfolio by using the Swarm algorithm (PSO). The researchers tried to test the possibility to adapt PSO as one of modern approach to build the investment portfolio to reach its optimization and its efficiency. This paper contains theoretical framework, general introduction and some previous studies, some information about efficient and optimal investment portfolio, how to build these portfolios according to risk - and return trade off. The researchers reached encouraging results. The researchers analyzed data from Iraqi -stock Exchange (i.sx.iq). The results compared with published others about the same subject. Finally, the researchers concluded that there is an ability to apply this algorithm to build optimal investment portfolio.

Key word: Stock, Investments portfolios, Optimization algorithms, Swarm algorithm (PSO), optimal portfolios.

\section{I-Introduction}

The importance of the investment portfolio stems from the fact, that it is one of the financial instruments used to mobilize the financial surpluses available. The latter back out to institutions, individuals, economic sectors, which can run them towards investing in a scientific manner that maximizes returns and reduces risk. In addition to employing surplus funds, also, it expands the 
activities of financial institutions and investment companies that offer money investment services, advice and financial advice. It diversifies investment instruments, provides liquidity to financial institutions, and provides investors with the best options to invest their money with various investment tools for quick and secure profit. This research related to the optimization of the investment portfolio through the proposal of the research approach to optimization. The research based on a swarm algorithm for applying data on the shares of companies traded in the Iraqi market for securities. The results showed that this method can use to build a portfolio may exceed in its efficiency the portfolio that built in the traditional methods.

\section{II- Methodology Study}

\section{1-Research problem}

Investment in securities is always a risky investment because of the continuous volatility in the prices of securities and unstable market conditions. In order to reduce the multiple risks of financial markets and reduce their negative effects on investors, portfolio investment was one of the appropriate approaches to this. However, simply creating a portfolio does not necessarily mean reducing or minimizing risk, Therefore, financial scholars and specialists have sought to develop many principles, that deal with the theme of the portfolio how to reduce the surrounding risks. These led to the emergence of the idea of efficient portfolio and then the optimal portfolio, the efficiency and efficiency of the portfolio is still the subject of research and attention by specialists because the risks are still plagued by financial investments and the multiple methods of portfolio building, diversification and regulation did not eliminate the risks. Hence, the research problem was how to arrive at a new method to build and formulate the optimal portfolio through the adoption of one of the operational research entries for this purpose.

\section{2-research importance}

The research is important because it represents an attempt to formulate a new approach to build an efficient portfolio and access to the optimal portfolio using one of the methods of operational research (bird flock algorithm (PSO)), which contributes to ensuring the efficiency and optimization of the investment portfolio

\section{3-Research goal}

The objective of the research is to test the possibility of using operational research (bird flu) to reach an efficient portfolio, which will add a new dimension to the theory of the portfolio. It contributes to enhancing confidence in the financial markets, especially when comparing the traditional portfolio theory with this new approach, which enhances the credibility of scientific methods in the practice of financial investment

\section{4-Research hypotheses}

The search based on two hypotheses:

1-Particles Swarms Algorithm (PSO) can use to build an efficient investment portfolio.

2- Particles Swarms Algorithm (PSO) can use to reach the optimal investment portfolio. 


\section{5-The research sample}

The research sample consists of a group of companies listed in the Iraqi Stock Exchange for the years $(2015-2016)$

\section{III-Literature Review}

The issue of efficiency and optimization of the investment portfolio has been the focus of many studies and scientific thesis. Campbell et al., 2001 presented a study entitled "Optimal Portfolio selection in VAR framework". It aimed at developing a model for selecting the components of portfolio. A study of the application of a sample of shares traded in the S\&P index and long-term US bonds, by using weekly and monthly returns for a period of 10 months. The researchers concluded that the use of the value which exhibited to a risk measure in the selection of the components of the portfolio. The latter is differently about those chosen it by using the standard deviation scale.

At 2004, Engles [19] presented the study entitled" Portfolio Optimization: Beyond Makowwitz". It is an applied study on a sample consisting of (7) shares with a high market value in the index of Dutch AFX. It focused on improving the Markowitz theory. This improving made the optimal portfolio that is more applicable. The researcher concluded that the Telser model works with all types of probability distribution of returns.

Muller at 2005 [20] introduced his study entitled "Constrained portfolio optimization". It pointed out that the optimization of the investment portfolio is the cornerstone of modern financial theory. It has a particularly important in selecting the optimal portfolio for a professional investor, and for pricing financial assets in an incomplete market. The researcher employs the mathematical methods. The latter used to enter the random variables as a sequential for reaching to maximize retuning portfolio or reduce risk for reaching to its optimality. "Analyze international financial investments and build efficient portfolio in emerging stock markets" is a study in which is presented by AlKhafaji at 2006 [5]. It's a study applied on (17 emerging (early) markets). The factors, opportunities and risks associated with returns, which naturally, related with an investment in this market, they analyzed and reviewed. The researcher concluded that building a portfolio using the market capitalization criterion is the best in allocating securities and building an efficient portfolio.

Ashish at 2007 [12] presented his study entitled" Essay on volatility derivatives and portfolio optimization", it discussed the use of volatile derivatives in portfolio building and asset allocation, as well as strategies for building investment portfolios based on the principle that the final value is a function of an asset price. In fact, the researchers' efforts will not stop. Many studies discuss the investment portfolio, where this paper represents a simple idea that continued research efforts in the development to build investment portfolio.

\section{IV- The concept and importance of the investment portfolio}

An investment portfolio is a group of assets owned by an investor. The latter retains it in order to obtain returns and profits. It is also a set of assets consisting of shares and bonds held by the investor. In addition, it is a combination of assets, which give the investor the best swap between return and risk. Rarely, the investor invests all his money in one asset [24]. It is a compound 
financial instrument from a mix of assets; the purpose of it is to obtain the highest return with the least risk [2]. It is also known as an existing or perceived returns held by the investor in order to achieve high return and low risk [21]. Whereas, Al-Dunwoody defined it as a diversified mix of assets, the purpose of owning them is to achieve the highest returns at an acceptable level of risk [1]. An efficient portfolio defined as a portfolio that offers the highest expected return with any degree of risk or minimum degree of risk with any expected return [7]. Based on the above, one can define an investment portfolio as a set of assets that the investor aims at forming it to achieve the right return and reduce the risk, where this is done by diversifying the assets that will form the investment portfolio upon it formed. One of the most important objectives of the investment portfolio is the balance between return and risk. Other objectives can also be formulation to meet the liquidity requirements. Most financial institutions resort to using the investment portfolio to manage their liquidity, pay off their sudden or sudden commitments and avoid financial difficulties by liquidating some of their assets in the finance market (Ramadan, 2003, 292). Herein, the investment portfolio can consider as a major source of liquidity for some institutions [8], in preserving the original capital [6]. Finally, the investment portfolios have common objectives: the most important of which is the stability of income flows according to the needs of different individuals and the growth of capital, because it is important for the investor to continue in the market [4].

\section{Assumptions of portfolio theory for investment}

Building an efficient portfolio and reaching an ideal portfolio has become possible. As it based on a broad ground of theoretical thought, practical application, and scientific means proved by proof. However, there are several assumptions that paved the way for the formulation of the theory of Markowitz:

-Investors look at investment alternatives based on the potential distribution of their expected returns over their retention period.

-The investors aim to maximize the expected benefit، each one of them has a curve showing the declining marginal utility.

-Investors view to the risk as a volatility in expected returns.

-Investors make their decision basis on expecting return and the underlying risk. The latter expressed by variation (or standard deviation), only.

- The investor is a risk averse. At a given level of risk, the investor prefers the higher yield, whereas, with the higher level of return, he favors less risk.

According to these assumptions, the efficiency of an asset or portfolio based on the fact, that it generates a higher return than any other asset at a given level of risk. Alternatively, the risk of it with specific level of return is less than any asset or another portfolio.

\section{VI-Foundations of investment portfolio construction}

The above assumptions paved the way for reaching the goal sought by any investor, or any financial market. The most important of these foundations can summarize as follows: 
- Diversification: For the purpose of reducing overall risk، it is best to diversify portfolio assets by adding or merging different asset classes when constructing an investment portfolio [10]. It is good to have a portfolio of assets that are different in their characteristics. This helps the investor to spread the risk on a range of different assets that ultimately helps to reduce risks.

- Determine the degree of correlation between the components of the portfolio: According to portfolio theory, the correlation between portfolio asset returns considers a key determinant of the portfolio's risk level. Poor correlation means that a decline in certain stock returns and may be offset the higher returns from other stocks. That is, total portfolio returns may significantly affect by adverse market conditions. This enhances the benefits of diversification and effectively reduces risk [10], [18], the opposite is true. If the degree of correlation is positive or high between the returns of the components of the portfolio. As this means, that they affected together. Therefore, the impact is negative, and the risk is high in inappropriate conditions or economic crises occur.

-Determining the weights of portfolio investments: The weight of each investment in the portfolio (the amount of that investment of total portfolio components). This plays a role in reducing risk, increasing returns or reaching both goals. The strength of the correlation between the returns of portfolio assets and the risk premium of each asset can determine the validity of that asset so that it can encourage the investor to include it in his portfolio. The appropriate weight then calculated for each asset to achieve the best swap between returns and risk [18].

-Risks measurement: The diverse risks surrounding portfolio investment reduce portfolio efficiency, so investors, financial analysts and finance scientists work to diagnose and identify risks. This is stated below, to be determined for developing manners, methods and mechanisms to reduce or eliminate its effects. It is worth mentioning that the methods of diagnosis of risk have been developed and the specialists developed methods and mechanisms of scientific and mathematical advanced for purpose of identifying risks and identify them clearly. Although Markowitz's theory has identified a measure of risk as standard deviation and variance. The measurements of risk have developed significantly with the development of statistical and computer methods. These sophisticated methods can diagnosis and calculate of risks with more accurate.

\section{VII - Efficiency and optimization of the investment portfolio}

The concept of efficiency and optimization of the investment portfolio represents a cornerstone of modern financial theory. This concept connects the theory of financial markets with the theory of microeconomics (the subject of marginal utility). This has several aspects in the framework of access to efficiency and optimization of the following:

\section{1-The principle of sovereignty and control}

The efficient portfolio accessed by means of using the principle of sovereignty and control. The latter refers that in each possible set of portfolio, in each conservative group one can find a portfolio dominate and control on other possible portfolios. If two or more portfolios are equal in terms of risk, the portfolio with higher return will consider dominates and controls. Because, it is the best and the top, and it chosen and neglect the rest of the portfolios. Whereas, if two portfolios are equal in terms of return. Herein, the portfolio that prevails be at least risk. Based on this principle, the investors will have a range of efficient portfolios that dominate and control to other 225 
portfolios. Then there will be an efficient limit, which includes all the efficient portfolios (the most efficient), which can obtain from the possible portfolios.

\section{2- indifference curves and optimal portfolios}

The investment portfolio depends on using indifference curves for the purpose of access to the optimal portfolio. This curve is a curve that consists of a set of portfolios that offer to the investor the same level of saturation in terms of return and risk, it reflects and reduces the marginal benefit. Each investor has its own line. This curve reflects all the preferences for return and risk, and it is different from the curve of any other investor. The investor (a) will be charged an average return on investment of $10 \%$, if the risk level is $8 \%$, and if the risk rises to $10 \%$, the return rate is only $12 \%$ , whereas, the investor (B) will not be charged upon these levels of risk unless he obtain an average return on investment equal to $14 \%, 16 \%$ respectively. Herein, the investor has a certain degree of acceptance or risk appetite reflected in the rate of return that satisfies (satisfies), and achieves the appropriate benefit at certain levels of risk. The investor's optimal portfolio represents the portfolio at the point at which the investor's curve touches the efficient limit of the available portfolios, which can synthesize from the set of stocks under consideration as in Figure 1

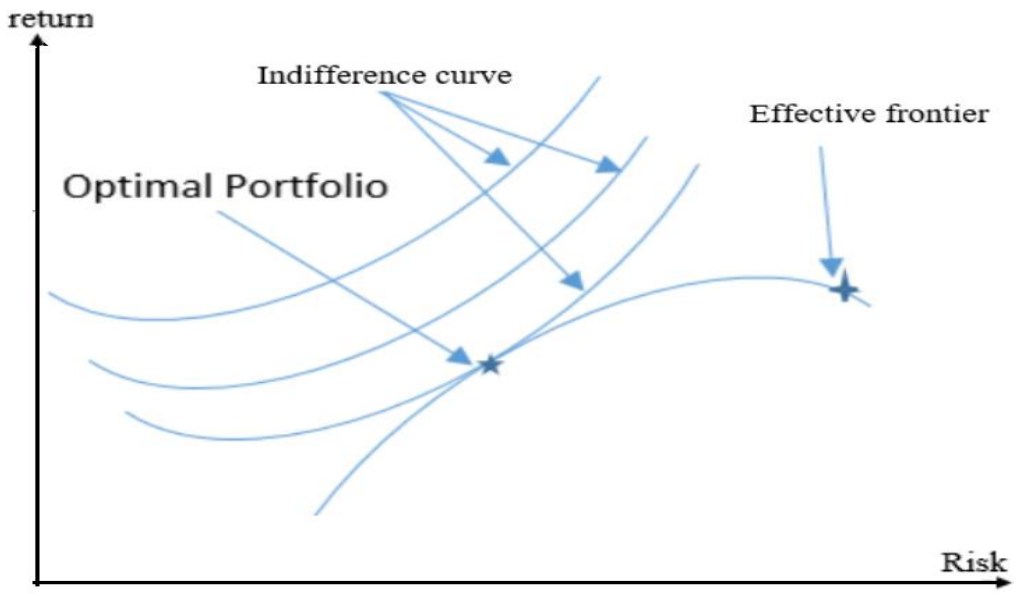

Figure (1)

Optimal portfolio and Effective limit

\section{3-Optimal portfolio and capital market line}

The capital line is a new efficient limit that consists of a portfolio of efficient portfolios when they contain risk-free securities (treasury transfers, high quality government bonds). An asset whose expected return known, and is its interest rate, which is often fixed or stable over a period. Additionally, its return has no association with the proceeds of the risky assets in the portfolio [19] [. Here its return has the form of a straight line that reflects linearly the reciprocal relationship between return and risk for an efficient portfolio. The portfolio risk was measured by the standard deviation of its returns. This line formed according to the equation of the capital market line as follows:

$R_{p}=R_{f}+\left(\frac{R_{m}-R_{f}}{\delta_{m}}\right) \delta_{p}$

Where, 
$R_{p}$ : Return of the market portfolio.

$R f:$ Risk Free Rate of Return.

Rm: Standard deviation of the market portfolio.

$\delta_{p}:$ Standard deviation of portfolio.

In Figure (2), the optimal portfolio is located at the point of contact of the investor's line (Investor B) with the capital market line (point $\mathrm{m}$ ) if the portfolio contains risk-free securities. The reason for this is that the investor will have a new curve both higher (higher benefit, whereas, a portfolio containing risk-free securities and a higher curve (B) means that the investor will demand a higher return at the same risk level for the portfolio when it contains risky assets only. The portfolio was located at the point of contact curve (investor $A$ ) with the effective limit at point (k).

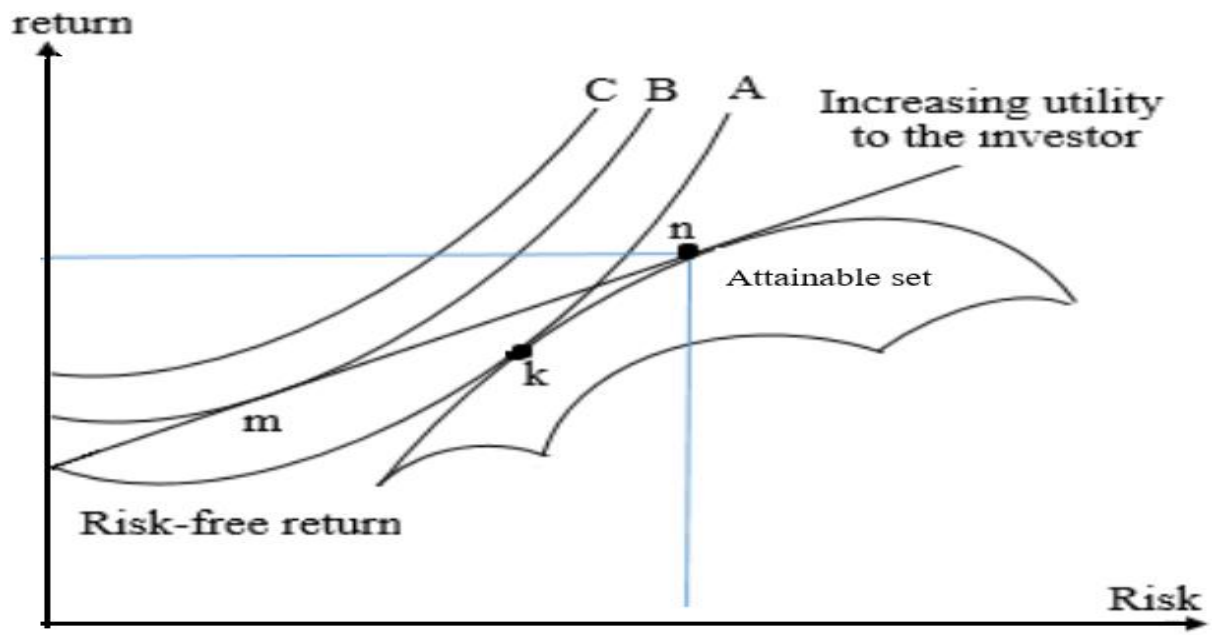

Figure (2)

The optimal portfolio

\section{4-The aspect of behavioral finance}

Behavioral finance is a trend in finance management; assumptions of other efficiencies are not necessarily identical with the assumptions of Markowitz, especially the assumptions regarding investor rationality, as the behavioral trend sees that there are many decisions of investors based on the effects of psychological and behavioral.t is not rational, as the financials-men used to point out. We should not expect people to act rationally with regard to their investments [7]. Herein, the optimization according to the vision of the behavioral approach influences by the personal attitudes of investors and the issues that push them to take the investment decisions. The problem of optimization is how to distribute the capital of the portfolio among the investment tools, and then follow the profitability constantly to adapt the components, according to the performance (returns) of those components [11].

\section{VIII- constructing an efficient investment portfolio using optimization algorithms}

Constructing an efficient investment portfolio is something that investors and financial analysts are interested in the finance market. In addition, the financial management scientists have 
formulated the idea of the portfolio of efficient and optimal. These ideas are developed continuously. The maturity of an optimization idea of investment portfolios has crystallized in scientific theories. The latter has made its way to the actual application in the financial markets and has led to an efficient market. In addition, it helps to diversification and giving doses of confidence to the financial markets, which is constantly suffering from turmoil and volatility, and is surrounded by the risks, which arise from many factors, such as:

- Speculations that create artificial opportunities and events by speculators for the purpose of making extraordinary profits at the expense of other investors.

- The continuous volatility in the prices of securities arising from factors of supply، demand، market conditions and the conditions of the companies themselves. This environment has given and added importance to the concept of efficient portfolio.

\section{1-The classic Particle Swarm Algorithm (PSO)}

At 1995, Kenndy \& Ebehant proposed Particle Swarm Algorithm (PSO) in their paper [13]. This algorithm based on the behavior of the swarm of insects, birds and fish, it simulates the behavior of these societies. Each individual (Particle) in swarm's flock behaves in a way, that is in harmony with the group by means of using the acquired intelligence, and collective of swarm detects a good path that leading to food. The behavior of that particle will enable the other members of the swarm to follow the new path if they know it. It is worth mentioning that the algorithms inspired by the behavior of life is one the methods of optimization based on the intelligence of the swarm. In addition, it is against the genetic algorithms based on assessment, which can call the genetic evolutionary algorithms.

The swarm algorithm composed of a community (population) that called swarm. The latter consists of individual, which called particles. The swarm is defined as a set $(\mathrm{N})$ of particles.

$S=\left\{x_{i 1}, x_{i 2}, x_{i 3}, \ldots, x_{i N}\right\}$

Where, each particle represents a point in a D direction-oriented space.

$$
x_{i}=\left[x_{i 1}, x_{i 2}, x_{i 3}, \ldots, x_{i D}\right]^{T} \in A, \quad i=1,2,3 \ldots, N
$$

Where, $A \subset R^{D}$ is a search space, and, $f: A \rightarrow Y \subset R$ represent the objective function, in order to maintain the simplicity of the description, we assume that $A$ falls within the feasible search space of the problem that studied. $(\mathrm{N})$ uses to identify the parameter of algorithm, the objective function is $f(x)$ in which is supposed to be specific and unique to all points.

So,: $f_{i}=f(x) \in Y$. The particles move repetitively in the search space (A). Automatic particle location control for interchangeable position called velocity, which defines as follows:

$$
V_{i}=\left[v_{i 1}, v_{i 2}, v_{i 3}, \ldots, v_{i D}\right]^{T}, \quad i=1,2,3 \ldots, N
$$

In addition, the velocity repetitively updated to provide the ability of particles potentially visit any area in the search space. Adding the (t) Counter to the steps of the above variables tell us to the current location of the particle (i) as $x_{i}^{t}$ and its velocity as $v_{i}^{t}$. 
The basic idea of PSO is to intelligently exchange information about the values of the best local position (local best), best global position (global best). However, the velocity updated according to the information that obtained from the previous steps of the algorithm.

In terms of memory, each particle can store the best location (best position) that it reached during the search process. The group $(\mathrm{P})$ represents the memory of swarm (s), where:

$$
b_{\text {best } i} i=\left[p_{i 1}, p_{i 2}, p_{i 3}, \ldots, p_{i D}\right]^{T} \in A, \quad i=1,2,3 \ldots, N
$$

The particles visited these positions, where these positions can define as follows:

$$
\text { pbest }^{t}=\arg \min _{s \leq t} f_{i}^{t}
$$

The best position ever visited called Global Best. It is reasonable to share this critical information. Therefore, (gbest) combines the best location with the best function value in $\mathrm{P}$ at the step (reputation): $g b e s t^{t}=\arg \min _{t} f\left(\right.$ pbest $\left._{i}^{t}\right)$

The traditional PSO, proposed by Kennedy and Eberhart [14], expressed in the following equations: $v_{i j}^{t+1}=v_{i j}^{t}+\emptyset_{1} \beta_{1}\left(\right.$ pbest $\left._{i j}^{t}-x_{i j}^{t}\right)+\emptyset_{2} \beta_{2}\left(g b e s t_{j}^{t}-x_{i j}^{t}\right)$

$$
x_{i j}^{t+1}=x_{i j}^{t}+v_{i j}^{t+1}
$$

In the traditional PSO, the particles have the possibility to fly outside the search space. The original technique proposed sample way to avoid this problem. It is surround the velocities. That is, each individual of $V_{i}$ rest within the range $\left[-\mathrm{V}_{\max },+\mathrm{V}_{\max }\right]$ which is called velocity clamping, where the thump role to initialize the velocity Vmax that may not be clear, and unfortunately, it related to the performance of the algorithm, which needs to balance exploration and exploitation (i.e., exploring and exploiting positions).

The coefficient factor of $X$ for the constraint was presented by Clerc and Kennedy [15] in order to update the velocity equation, herein, on can see, this formula assume the $\left(\mathrm{V}_{\max }\right)$ velocity limit in which is no longer necessary [22]. This adherence is an alternative manner of controlling particle behavior in the swarm in this algorithm.

$$
\begin{gathered}
v_{i j}^{t+1}=x\left\{v_{i j}^{t}+\emptyset_{1} \beta_{1}\left(\text { pbest }_{i j}^{t}-x_{i j}^{t}\right)+\emptyset_{2} \beta_{2}\left(\text { gbest }_{j}^{t}-x_{i j}^{t}\right)\right\} \\
x=\frac{2}{\left|2-\emptyset-\sqrt{\emptyset^{2}+4 \emptyset}\right|}, \text { where } \emptyset=\emptyset_{1}+\emptyset_{2}, \emptyset>\ldots \ldots \ldots \ldots \ldots \ldots \ldots \ldots \ldots \ldots \ldots \ldots \ldots \ldots \ldots
\end{gathered}
$$

Where, the numbers $\mathrm{x}=0.7298$ and $\emptyset_{1}=\emptyset_{2}=2.25$. Where, this is currently the default number $\mathrm{f}$ restriction transactions. This restrictive approach is called (the canonical particle swarm algorithm).

\section{Standard algorithm of PSO.}

Input. Population with size $\mathrm{m}$, and with various parameters.

Output. The best value of particle i gBest.

1: Initialize (population, parameters, all particles vectors, velocity vector).

2: Generate $\overrightarrow{X^{\imath}}$ as a position of each particle $i$. 
3: Set $P_{\text {Best }}^{i} \leftarrow \overrightarrow{X^{\imath}}$.

4: Set $\overrightarrow{V^{\imath}}$ as a vector of velocity.

5: Repeat step.

6: While (The iterations (or runtime) limit is not performed).

7: For $\forall$ particl $i \in m$ do.

8: $\quad$ Compute $F_{\overrightarrow{X^{i}}}$

8: If $F_{\overline{\text { Pbest }}}>F_{\overrightarrow{X^{i}}}$ then,

9: $\quad P_{\text {best }} \leftarrow \overrightarrow{X^{\imath}}$.

10: $\quad$ end if.

12: end for

13: put the particle with value $\left(F_{\overrightarrow{\text { Pbest }}}\right)$ as a gBest.

14: $\quad$ for $\forall i \in m$ do.

15: $\quad$ Compute velocity of particle according equ.(8).

16: $\quad$ Update position of particle according to equ.(9).

17: end for.

18: end while

19 Return gBest.

\section{2-Types of Swarm algorithms}

The PSO algorithm can divide into three sections:

1- Parametric Approach Algorithm: it interest to study the different parameters involved the velocity that is studied on the performance of the swarm. These parameters include vectors such as damping weight, cognitive and social vectors. Studies in this field are trying to create a base or provide new milestones to improve results. The study of the parameter can be classified into three categories:

A) The first category includes strategies for the value of the weight of damping and / or other parameters in which the weight of the damping and / or other parameters are fixed or random [26].

B) The second category defines weight of damping and other parameters as a function of time or step number. This may be a time strategy for varying the weight of damping [23].

C) The third category is the dynamic parameters strategies, which include the methods of using the reference to the memory of beginning the system and then the value of the weight of the 
damping [14]. In addition, to learn how to adjust the acceleration factor to balance the local and global survey of the swarm [16].

2 - Algorithm to improve the swarm: Take into account the different communication structures within (inside) swarm.

3. Hybrid algorithm: Incorporates other analog algorithms such as genetic algorithm, crossalgorithm, ants algorithm ... This class is related to the development by hybridization by adopting triggers for other analog algorithms, for example Chen et al. They provided a PSO hybridization algorithm with Extreme Optimization (EO) to improve PSO for local search capabilities. The EOPSO algorithm can avoid premature convergence of complex multiplexing problems [17]. They proposed an algorithm for PSO hybridization with an ACO antigen algorithm [25]. Shieh et al. [9]. Chen et al. [3] and Marinakis and Marinakis [27] were able to hybridize the cross-algorithm with the PSO [10] algorithm. It is worth noting hybridization algorithms improve performance and improve execution time. All these studies were concerned with the swarm's battles.

\section{3-An optimal investment portfolio based on the proposed algorithm}

PSO algorithm was used to obtain an optimal portfolio, which should be at a higher return and less risk. The weights were initially assumed to build optimal portfolio. These weights represent a matrix with only one row and several columns. They representing the proposed the weight of shares in the portfolio, where the sum of these weights is equal to (1). Each particle in the proposed algorithm is a specific stock order. Herein, the particle in the matrix has the same size as the weight matrix of portfolio, but its components are numbers from (1) to (n), which represents the number of shares in the proposed portfolio.

The idea of the algorithm is changing the positions of shears with the survival of weights in specific locations. The algorithm continue to change the shears' positions until to reach for the best compatibility of the portfolio, which will be the best portfolio. The latter composed of the greatest relative value of rate of return that divided on risk in which represent the optimal portfolio.

Note, the researchers did not find a way to use this algorithm to build an investment portfolio, but that does not mean, they first using it, but they hope that they apply it in this field at first time; therefore, they call any one who fined it to refer to this information.

\section{4-Steps of the proposed algorithm}

The researchers found that the algorithm should put in simple steps in order to give a clearer vision of its work, therefore, it was proposed to put as follows:

Step 1: - Put the initial data that represent the values of the stocks in the matrix, its rows represent the stocks that will contribute to the composition of the optimal portfolio.

Step 2: Calculate the return for each stock by calculating the rate of each row in the data of the matrix.

Step 3: - We put a vector weight or matrix in one row so that each stock has a certain weight, where the total weights equal to one. 
Step 4: - Initialize the initial values that will start with the swarm algorithm as follows: Bestfun is the best function or best return that represents to the return of the portfolio. Best $t_{\text {run }}$ was the best execution of the several times it was implemented, Best Variable $_{\text {is }}$ the best variable which gave us the best return for the best portfolio, $T_{\text {Time }}$ represents to the time taken for the overall implementation of the algorithm.

The proposed algorithm was applied to classical algorithm procedures on data obtained from the daily data of the Iraq Stock Exchange.

\section{IX-Results}

All parameter should be best before test the data of study, in order to obtain the best results, the algorithm was implemented after installing the parameters of the suggested swarm algorithm as shown in the table (1).

Table (1) Adjust parameters of algorithm

\begin{tabular}{|c|c|c|c|c|c|c|}
\hline Run & $\mathrm{w}_{\max }$ & $\mathrm{w}_{\min }$ & $c_{1}$ & $c_{2}$ & Converge & Time \\
\hline 1 & 0.9 & 0.4 & 2 & 2 & 5 & 39.974531 \\
\hline 2 & 0.8 & 0.4 & 2 & 2 & 4 & 27.561557 \\
\hline 3 & 0.7 & 0.4 & 2 & 2 & 4 & 27.555610 \\
\hline 4 & 0.5 & 0.4 & 2 & 2 & 4 & 27.296879 \\
\hline 5 & 0.4 & 0.4 & 2 & 2 & 4 & 27.283587 \\
\hline 6 & 0.3 & 0.4 & 2 & 2 & 7 & 27.183052 \\
\hline 7 & 0.9 & 0.3 & 2 & 2 & 5 & 27.855710 \\
\hline 8 & 0.7 & 0.2 & 2 & 2 & 4 & 26.945043 \\
\hline 9 & 0.5 & 0.1 & 2 & 2 & 4 & 27.379710 \\
\hline 10 & 0.4 & 0.5 & 2 & 2 & 4 & 26.817315 \\
\hline 11 & 0.3 & 0.6 & 2 & 2 & 7 & 27.273864 \\
\hline
\end{tabular}

Following parameters were chosen, which gave us the best results in terms of the fastest convergence and time. Figure (1) refers to adjust the parameters of algorithm.

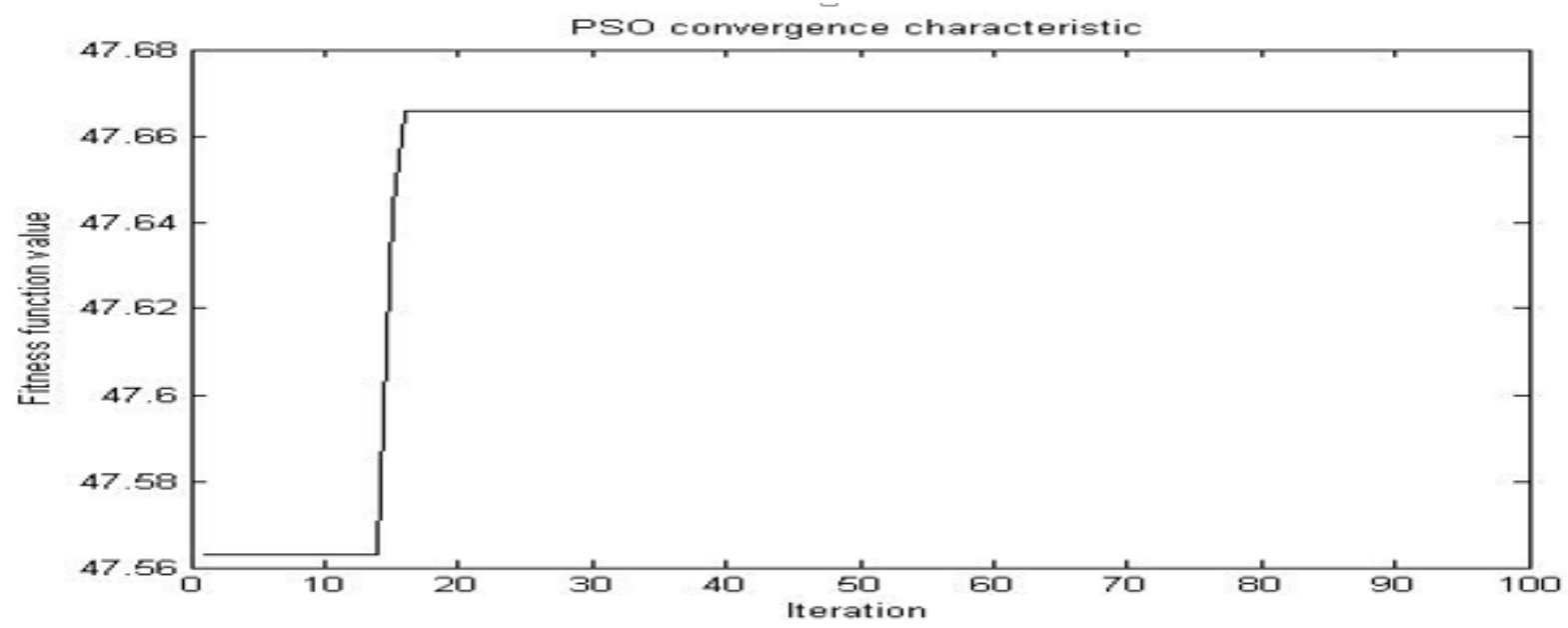

Figure (1) 
The convergence of implantation of algorithm's parameters

After the parameters were installed, the algorithm was implemented with (15) implementation and (100) repetitions per implementation and with a size of population is (25).

Table (2)

Best parameters of algorithm

\begin{tabular}{|c|c|c|c|c|c|c|}
\hline Run & $\mathrm{W}_{\max }$ & $\mathrm{W}_{\min }$ & $c_{1}$ & $c_{2}$ & Converge & Time \\
\hline 8 & 0.7 & 0.2 & 2 & 2 & 4 & 26.945043 \\
\hline
\end{tabular}

The optimal portfolio obtained after implementation shown in table (3), and the possible portfolios are distributed in the search space as shown in Figure (2).

Table (3)

The optimal portfolio and the weight of shares.

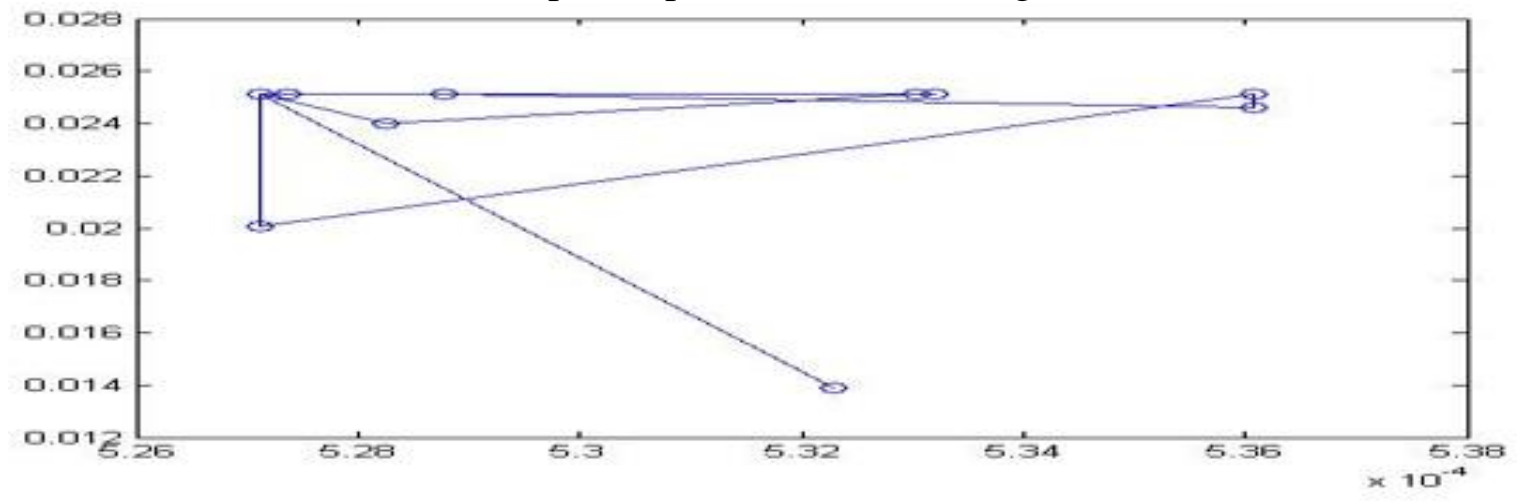

\begin{tabular}{|c|c|}
\hline \multicolumn{2}{|c|}{ Optimal portfolio with return: 0.025125000000000} \\
\hline Share & Weight \\
\hline 1 & 0 \\
\hline 2 & 0.274 \\
\hline 3 & 0.156 \\
\hline 4 & 0.120 \\
\hline 5 & 0.450 \\
\hline
\end{tabular}

Figure (2)

The set of possible portfolios in the search space 


\section{X11-Conclusions}

A- Portfolio investment in financial assets has become an important economic activity

B- The investment portfolios consisting of a set of financial guises are the best way to practice financial investment

C- Building an optimal and efficient portfolio requires the use of scientific methods.

D- Operational research methods can be useful in building an efficient portfolio.

E- The swarm algorithm provides an efficient way to reach the best swap between return and risk.

\section{XIII-Recommendations}

A- The need to adopt scientific methods when investing in financial assets

B-The need to identify the risks inherent in any financial investment and accurately measure them and compare them with the expected returns from that investment before starting to be selected as a component of the investment portfolio.

C- The need to continue to search for the best scientific methods to measure returns and risk diagnosis for the purpose of making financial investment profitable and away from various risks. D- The adoption of methods of operations research for measuring returns, risk diagnosis and investment portfolio building in addition to the traditional methods currently used.

\section{References}

[1] A.B. Al., Al-dawoudy, (2014). " Effect of portfolio management strategies on their returns and risks (applied study on a sample of companies listed in the Iraqi Stock Exchange)". Faculty of Management and Economics, University of Tikrit, Master Thesis, 20.

[2]Ah. B, Al-anee. Al-anee, Ahammed Battal (2008)"Use of quadrate programming to determine the optimal portfolio investment: with reference private sector banks in the market of Iraq securities" journal of Faculty of science of administration and economics no.2.

[3] A.-L. Chen, G.-K. Yang, and Z.-M. Wu,(2006)" Hybrid discrete particle swarm optimization algorithm for capacitated vehicle routing problem," Zhejiang university SCIENCE A, vol. 7(4), pp. 607-614, 2006.

[4] A. S. Saeed \& F.H. Mouhammed "Investments and its tools in market financial, Analytic study of the reality of the financial market Iraqi, Western and USA. Dar Al Doctor of science and administrative and economic.

[5]A. J. Al Khafaji, (2006)" Analysis of international investments and building the efficient portfolio in the new market -Empirical study. . Faculty of Management and Economics, University of Baghdad, Doctorate Thesis, (unpublished).

[6]D. Ma. Mouhammed (2007)" Financial markets" Alsherouq to post and distribution, Amman,_Jordan .

[7] F. Brigham, Eugene, \& Ebrhardt Mechael, (2005)."Financial management, theory and Practice". Middle East and Afrrica Edition, South-Westren, Gengage Learning.

[8] H. H. George \& Simonson, Donald G., (1999), Bank Management Text and Cases, 5th. ed John Wiley \& Sons, Inc Hall, New Jersey.

[9] H.-L. Shieh, C.-C. Kuo and C.-M. Chiang, (2011) "Modified particle swarm optimization algorithm with simulated annealing behavior and its numerical verification," Applied Mathematics and Computation, vol. 218, pp. 4365-4383.

[10] j. G. Lawrence (2006)"principal of managerial Finance" Eleventh Edition, Pearson Adison wisely, 2006.

[11] j. Hanqing, (2004)"Continuous-Time Portfolio Optimization" A thesis of Doctor Degree in system Engineering and Engineering management in Hong-Kong University.

[12] J. Ashish. (2007)"Essay on Volatility Derivatives and portfolio Optimization" A doctor of philosophy thesis. Columbia University.

[13] J. Kennedy \& R. Eberhart (1995). "Particle swarm optimization," in Proceedings of IEEE

International Conference on Neural Networks IV , pp. 1942-1948.

[14] J. Liu, X. Ren, and H. Ma, (2012) "A new pso algorithm with random c/d switching," Applied Mathematics and Computation, vol. 218, pp. 9579-9593. 
[15] M. Clerc \& J. Kennedy, (2002). "The particle swarm - explosion, stability, and Convergence in a multidimensional complex space," IEEE Transactions on Evolutionary Computation, vol. 6(1), pp. 58-73.

[16] M. Gang, Z. Wei, and C. Xiaolin, (2012) "A novel particle swarm optimization algorithm based on particle swarm migration," Applied Mathematics and Computation, vol. 218, pp. 6620-6626.

[17] M.R. Chen, X. Li, X. Zhang, and Y.-Z. Lu,(2010) "A novel particle swarm optimizer hybridized with extremely optimization," Applied Soft Computing, vol. 10, pp. 367-373, 2010.

[18]M.I. Hindy, (2004). "Modern thought in the area of investment". Alexandria, Egypt Second Edition.

[19] M. Engles. (2004)."Portfolio Optimization beyond Markowitz" A master thesis in University of Leiden.2004.

[20] M. Stephen (2005)." Constrained portfolio Optimization "Thesis submitted to Callen University.

[21]M. Mouhammed, (2009)"Administration of investments: Framework theoretical and applications process" House of Weal to post, Copy 5.

[22] R.C Eberhart \& Y, Shi, (2000) "Comparing inertia weights and constriction factors in particle swarm optimization" In proceedings of the IEEE Congress on Evolution Computation, pp. 84-8.

[23] T. J. Ai and V. Kachitvichyanukul,( 2008) "A study on adaptive particle swarm optimization for solving vehicle routing problem," in Proceedings of the $9^{\text {th }}$ Asia Practical Industrial Engineering $\&$ Management Systems Conference, pp. $2262-2268$.

[24] V.K. Bhalla, (2006) "Fundamentals of Investment management" S.Chand \& Company LTD. New Delhi. India.

[25] W. Deng, R. Chen, B. He, Y. Lu, L. Yin, and J. Gup, (2012) "A novel two-stage hybrid swarm intelligence optimization algorithm and application," Soft Computing, vol. 6(10), pp. 1707-1722.

[26] Y. Shi and R. C. Eberhart,(1998) "A modified particle swarm optimizer," in Proceedings of the Evolutionary Computation, 1998, pp. 69-73.

[27] Y. Marinakis and M. Marinakis, "A hybrid multi-swarm particle optimization algorithm for the probabilistic traveling sales problem,” Computers \& Operations Research, vol. 37, pp. 432-442, 2010. 